\title{
Aspectos relevantes sobre a cercosporiose do quiabeiro no Brasil: etiologia, sintomatologia, epidemiologia e controle
}

Relevant aspects of okra Cercospora Leaf Spot (CLS) disease in Brazil: etiology, symptomatology, epidemiology and control

Carolina dos Santos Galvão ${ }^{*}$, Fabīola Teodoro Pereira', Fabricio Rodrigues',

Daniel Diego Costa Carvalho'

'Laboratōio de Fitopatologia,

Universidade Estadual de Goiâs (UEG), Rodovia GO 330, km 241, Anel Viário, Setor Universitário, CEP 75780-000, Ipameri, GO, Brasil

* autor correspondente

凶 carolgallvao@hotmail.com
RESUMO: Objetivou-se com esta revisão realizar um levantamento sobre a cercosporiose do quiabeiro, enfocando os aspectos mais relevantes para a doença no Brasil: características micromorfológicas do patógeno, sintomatologia, epidemiologia e controle da doença. Resumidamente, P. abelmoschi e Cercospora (C. hibiscina e $C$. malayensis) podem ser diferenciados baseando-se nas características dos conidióforos, enquanto C. malayensis e C. hibiscina são diferenciados pelo comprimento dos conidióforos e conídios. No Brasil, a cercosporiose está frequentemente associada às espécies $C$. malayensis e $C$. hibiscina, em que C. malayensis é uma espécie menos agressiva, causando manchas foliares escuras e arredondadas e, por outro lado, C. hibiscina é mais agressiva, causando manchas foliares escuras, irregulares e maiores que a anterior. O controle da cercosporiose na cultura do quiabeiro é baseado em práticas culturais e controle químico, pois não existe o controle varietal.

PALAVRAS-CHAVE: Abelmoschus esculentus, taxonomia de fungos, horticultura.
ABSTRACT: This review aimed to discuss the Cercospora Leaf Spot (CLS) disease on okra, focusing on the most relevant aspects of the disease in Brazil: pathogen micromorphologic characteristics, symptomatology, epidemiology and disease control. Briefly, P. abelmoschi and Cercospora (C. hibiscina and C. malayensis) are differentiated by the conidiophores characteristics, while C. malayensis and C. hibiscina are differentiated by length of the conidiophores and conidia. In Brazil, the CLS is often associated to C. malayensis and C. hibiscina, C. malayensis is a less aggressive specie, causing dark and rounded leaf spots, while C. hibiscina is more aggressive, causing irregular, dark and larger leaf spots. The control of the okra CLS disease is based on cultural practices and chemical control, since there is not varietal control.

KEYWORDS: Abelmoschus esculentus, fungi taxonomy, horticulture.

\section{Introdução}

O quiabo é um fruto proveniente do quiabeiro (Abelmoschus esculentus (L.) Moench), que é uma planta hortícola de origem africana pertencente à família das Malváceas. Tem alto valor nutritivo, medicinal e comercial, possuindo ciclo vegetativo rápido, de fácil cultivo e de alta rentabilidade. A cultura do quiabeiro é muito popular em regiões de climas 
tropical e subtropical (FARRAG, 2011; JAIN et al., 2012) e, devido à rusticidade e à tolerância ao calor, não exige grande tecnologia para seu cultivo (OLIVEIRA et al., 2003).

A cultura é muito apropriada para agricultura familiar, produzida no país e destinada quase que exclusivamente ao mercado interno. A produtividade média de quiabo no Brasil é de 20 a 40 toneladas ha ${ }^{-1}$ e os maiores estados produtores são Bahia, Minas Gerais, São Paulo e Rio Grande do Norte (PANERO et al., 2009). As cultivares mais conhecidas no Brasil são a cultivar Santa Cruz 47 e a cultivar Amarelinho AG-388 (GONÇALVES et al., 2009). Um dos maiores problemas que limitam a produtividade média brasileira de quiabo são as doenças (MASSOLA JUNIOR; BEDENDO, 2005; SOUZA et al., 2008). Os fungos são os principais agentes causadores de doença no quiabeiro, destacando-se a cercosporiose, causada pelo fungo Cercospora hibiscina Ellis \& Everh, como uma doença em expansão. Em condições de alta severidade, a cercosporiose pode causar desfolha total da planta (MASSOLA JUNIOR; BEDENDO, 2005).

Existem 20 registros de Cercospora sp. para o gênero Abelmoschus sp. no mundo, todos suportados por caracteres micromorfológicos. Dentre esses registros para o gênero Abelmoschus, já foram reportadas no Brasil as espécies C. abelmoschi, Pseudocercospora abelmoschi (Ellis \& Everh), C. malayensis f. Stevens \& Solheim (1931) e C. hibiscina como as principais (FARR; ROSSMAN, 2015). Existem poucas informações acerca da etiologia, sintomatologia, epidemiologia e controle da cercosporiose do quiabeiro. O que existem são apenas pesquisas ou trabalhos regionais relacionados à doença, enfocando manejo e controle alternativo (CATARINO et al., 2007; SOUZA et al., 2008). Uma revisão abordando a etiologia e sintomatologia da cercosporiose do quiabeiro é importante principalmente para auxiliar na diagnose da doença, pois a correta caracterização do patógeno ocorrente compreende parte de um processo de se direcionar às mais adequadas medidas de controle (VASCONCELOS et al., 2014). Este trabalho teve como objetivo realizar uma breve revisão sobre a cercosporiose do quiabeiro, enfocando os aspectos mais relevantes para a doença no Brasil, como características micromorfológicas do patógeno, sintomatologia, epidemiologia e controle da doença.

\section{Revisão Bibliográfica}

\section{Características micromorfológicas do agente etiológico}

O patógeno Cercospora hibiscina é pertencente ao Reino Fungi, Filo Ascomycota, Classe Dothideomycetes, Ordem Capnodiales, família Mycosphaerellaceae (MYCOBANK, 2015). De maneira geral, o fungo produz conidióforos curtos não ramificados, eretos, em tufos, de coloração marrom pálido, septados e surgem através da lesão da doença (FARRAG, 2011; BEGUM et al., 2012). Os conídios são bastante longos ou filiformes, multisseptados e hialinos, sendo produzidos na extremidade dos conidióforos, que se apresentam agrupados em feixes (BEGUM et al., 2012) (Figura 1).

$\mathrm{Na}$ fase anamórfica, ou seja, a fase imperfeita, a reprodução é realizada por meio de conídios, que são produzidos em conidióforos. Na fase teleomórfica ou fase perfeita, os esporos de origem sexuada, os ascósporos, são formados no interior de ascos, os quais se desenvolvem no interior de corpos de frutificação, predominantemente do tipo peritécio. A reprodução sexuada inicia-se a partir da plasmogamia. Em seguida, ocorrem a cariogamia e, depois, a meiose até a formação do asco ou asca, cujo conteúdo diferencia-se em ascósporos (BEDENDO, 2011). Existem relatos de três espécies do complexo Cercospora ocorrentes em plantas de quiabo: Pseudocercospora abelmoschi, Cercospora malayensis e C. hibiscina (Tabela 1). Para o correto diagnóstico da espécie ocorrente, é importante obter as dimensões de suas estruturas, que são o comprimento e a largura do conidióforo e dos conídios (Tabela 1), entre outras características que serão discutidas a seguir.

Em Pseudocercospora abelmoschi, são verificados loci conidiogênicos inconspícuos (pouco visíveis) ou
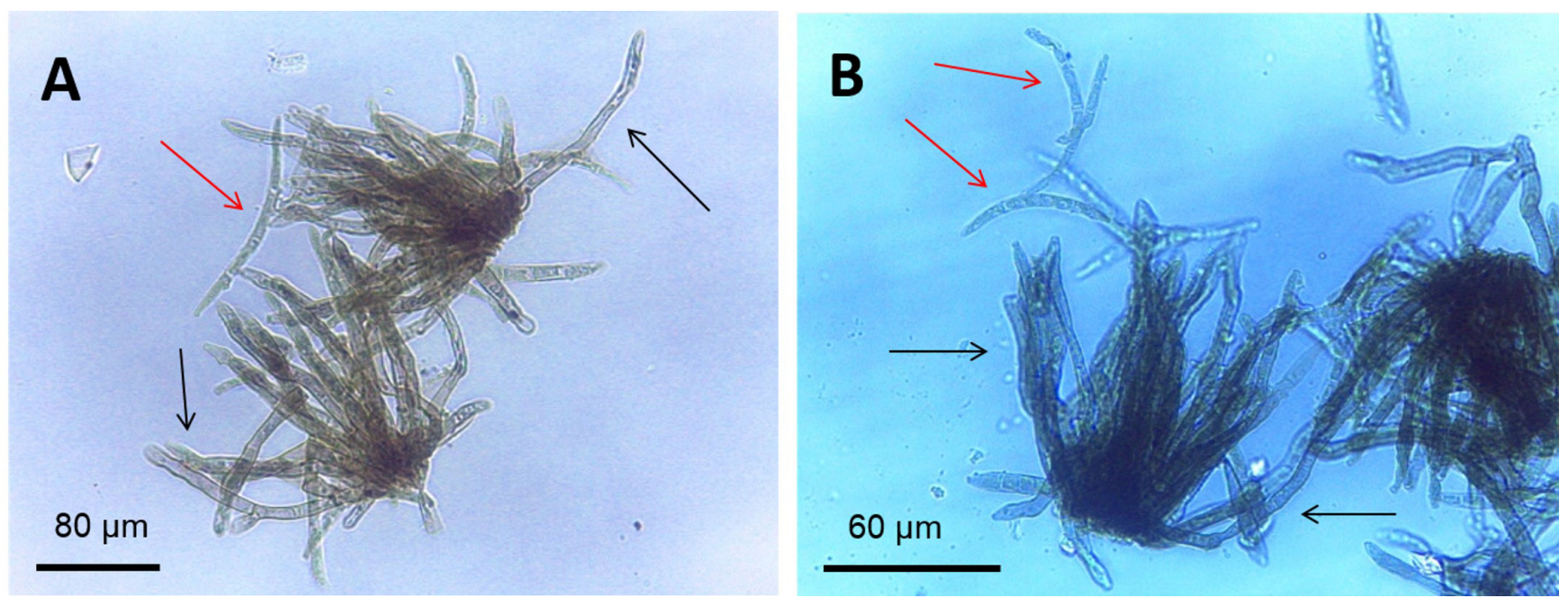

Figura 1. Imagens de Cercospora hibiscina obtidas de lesões em folhas de Abelmoschus esculentus encontradas em campo experimental da Universidade

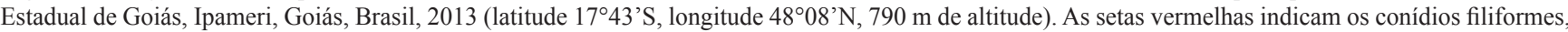
multisseptados e hialinos. Setas pretas indicam conidióforos curtos não ramificados, eretos, agrupados em feixes (tufos) e de coloração marrom pálido. 
subdenticulados, porém sempre não espessos e não escuros, um tanto quanto refrativos e visíveis na forma de diminutos anéis (BEGUM et al., 2012). Já em Cercospora sp., as espécies apresentam loci conidiogênicos conspícuos (mais visíveis), espessos, escuros, somente com um minúsculo poro central (FREIRE; BRAUN, 2009; BEGUM et al., 2012). Além disso, P. abelmoschi e Cercospora (C. hibiscina e C. malayensis) podem ser diferenciados baseando-se nas características dos conidióforos, pois os conidióforos em P. abelmoschi possuem comprimento menor $(10,0-56,0 \mu \mathrm{m})$ em relação às duas espécies de Cercospora (C. malayensis: 25,0-260,0 $\mu \mathrm{m}$; C. hibiscina: 150,0-1.000 $\mu \mathrm{m})$. Por fim, C. malayensis e C. hibiscina podem ser diferenciados, principalmente, quanto ao tamanho dos conídios, sendo os conídios de $C$. malayensis maiores em comprimento $(50,0-270,0 \mu \mathrm{m})$ do que os conídios de C. hibiscina $(20,0-80,0 \mu \mathrm{m})$. Também é válido salientar que os conidióforos de C. hibiscina $(150,0-1.000 \mu \mathrm{m})$ são maiores que os de C. malayensis $(25,0-260,0 \mu \mathrm{m})$ (Tabela 1).

Tabela 1. Características micromorfológicas de Pseudocercospora e Cercospora ocorrentes em folhas de Abelmoschus esculentus (quiabo).

\begin{tabular}{|c|c|c|}
\hline \multirow{2}{*}{ Espécie do fungo } & \multicolumn{2}{|c|}{ Dimensões das estruturas $(\mu \mathrm{m})$} \\
\hline & Conidióforo & Conídio \\
\hline $\begin{array}{c}\text { Pseudocercospora } \\
\text { abelmoschi }{ }^{1}\end{array}$ & $12,0-56,0 \times 2,5-5,0$ & $17,0-66,0 \times 3,5-5,0$ \\
\hline $\begin{array}{c}\text { Pseudocercospora } \\
\text { abelmoschi }\end{array}$ & $10,0-50,0 \times 3,0-5,0$ & $25,0-80,0 \times 2,5-4,0$ \\
\hline $\begin{array}{l}\text { Cercospora } \\
\text { malayensis }{ }^{3}\end{array}$ & $25,0-260,0 \times 3,0-5,0$ & $50,0-270,0 \times 2,5-4,0$ \\
\hline $\begin{array}{l}\text { Cercospora } \\
\text { hibiscina }^{4}\end{array}$ & $150,0-1000 \times 3,0-4,5$ & $20,0-80,0 \times 3,0-5,0$ \\
\hline
\end{tabular}

${ }^{1}$ Meeboon et al. (2007); ${ }^{2}$ Begum et al. $(2012) ;{ }^{3}$ Little (1987); ${ }^{4}$ Chupp (1954).

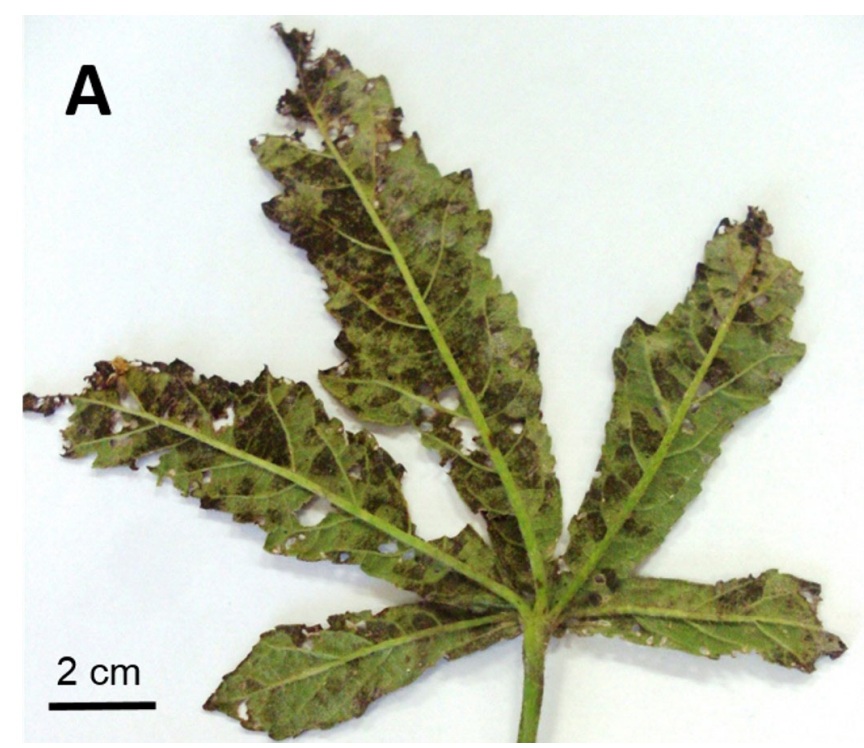

Recentemente, Farrag (2011) encontrou a mancha de Cercospora sp. em plantas de quiabo, em que foram verificados conídios delgados, ligeiramente curvos, com paredes finas, hialinos, multisseptados (3-6 septos) e com dimensões de $40,0-75,0 \mu \mathrm{m} \times 3,0-5,0 \mu \mathrm{m}$. Não dispondo das características dos conidióforos, Farrag (2011) limitou-se em identificar o fungo como Cercospora sp. Assim, nota-se a importância de se obter todas as características e dimensões de conídios e conidióforos especificados na Tabela 1 para um diagnóstico mais preciso. Além das características micromorfológicas e moleculares, existem diferenças quanto aos sintomas, as quais também auxiliam na correta diagnose.

\section{Sintomatologia nas folhas e fruto}

Não existem relatos na literatura que caracterizem os sintomas de cescosporiose quando há ataque de P. abelmoschi. Assim, no Brasil, embora já relatada a ocorrência de P. abelmoschi (MENDES et al., 1998), a cercosporiose está frequentemente associada a duas espécies de Cercospora sp., C. malayensis e C. hibiscina. Precisamente, C. malayensis é uma espécie menos agressiva e causa manchas foliares escuras, arredondadas e com bordos avermelhados, enquanto $C$. hibiscina é mais agressiva, causando manchas irregulares e maiores que as anteriores (MASSOLA JUNIOR; BEDENDO, 2005). Quanto à sua patogenicidade, o fungo C. hibiscina é específico para os gêneros Abelmoschus sp. e Hibiscus sp. (CHUPP, 1954), enquanto C. malayensis pode atacar também plantas dos gêneros Euphorbia sp. e Sphaeralcea sp. (LITTLE, 1987). De maneira geral, os sintomas da cercosporiose são observados, inicialmente, nas folhas mais baixas e mais amadurecidas como pequenas pontuações (FARRAG, 2011). Assim, na fase inicial, apresenta-se de cor verde oliva na parte superior (Figura $2 \mathrm{~B}$ ) e preta na parte inferior da folha (Figura 2A). À medida que ocorre o seu amadurecimento, passa a obter uma massa (composta de tufos de conidióforos) de coloração cinza-escura na face adaxial e

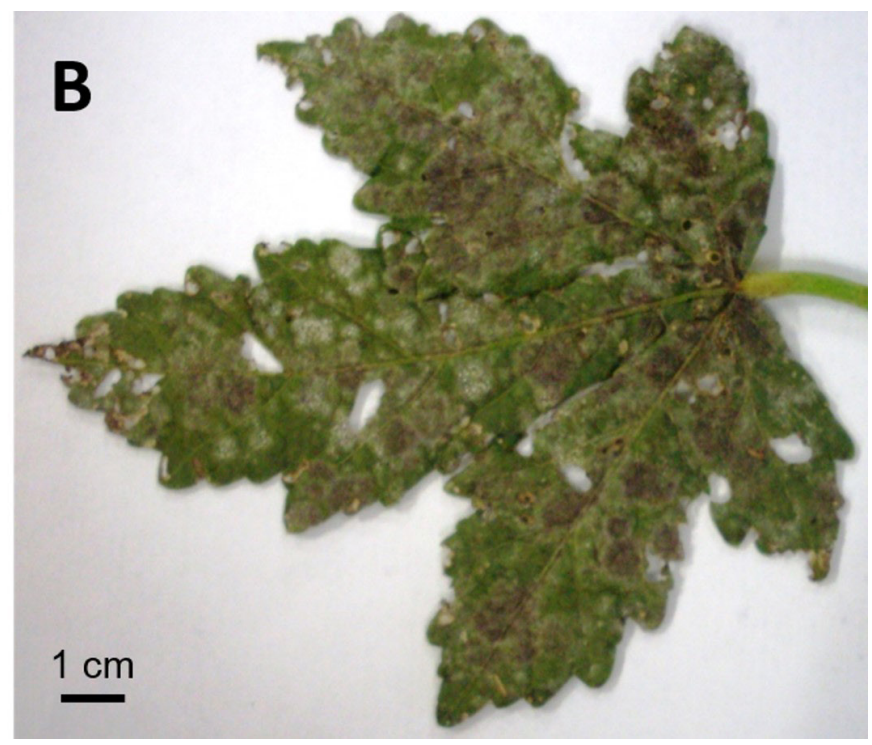

Figura 2. Folhas de Abelmoschus esculentus exibindo sintomas de cercosporiose, causada por C. hibiscina, Universidade Estadual de Goiás, Ipameri, 2013. (A) Manchas irregulares, escuras e fuliginosas observadas na face abaxial da folha de quiabeiro; (B) Manchas grandes (até $1 \mathrm{~cm}$ de diâmetro) de coloração verde-oliva a cinza-escura observadas na face adaxial da folha de quiabeiro. 
abaxial da folha (Figuras 2A e 2B). Em casos severos e com o contínuo desenvolvimento da doença, esta pode culminar na desfolha prematura das plantas (PAULA, 2011).

Em geral, os fungos que causam cercosporiose estão associados com manchas foliares, mas também podem causar lesões necróticas em flores, frutos, sementes, brácteas e pedicelos em uma ampla gama de climas em todo o mundo (BAKHSHI et al., 2012). Quando de ocorrência no fruto, as perdas são irreparáveis, pois a parte comercializada, uma vez atacada, deprecia o produto final a ser comercializado. Assim, quando em casos severos, a cercosporiose ataca os frutos, os quais passam a exibir manchas grandes, irregulares, de aspecto fuliginoso e com coloração verde-oliva a cinza-escura (Figura 3).

\section{Epidemiologia}

Os fungos cercosporioides estão amplamente difundidos como patógenos de plantas em regiões tropicais, com destaque para o Brasil (MEEBOON et al., 2007). No Brasil, a esporulação de $C$. hibiscina é favorecida por altas temperaturas (acima de $25^{\circ} \mathrm{C}$ ) e alta umidade relativa do ar (acima de $90 \%$ ), o que explica a maior ocorrência da doença durante verões chuvosos (MASSOLA JUNIOR; BEDENDO, 2005). A disseminação dos conídios produzidos nas lesões ocorre principalmente através do vento e por respingos de água de chuva ou irrigação. Embora os esporos de Cercospora necessitem de água para germinar e penetrar, o orvalho é suficiente para a infecção (AGRIOS, 2005). Na fase patogênica, o fungo penetra principalmente pelos estômatos, colonizando os tecidos vegetais mediante a produção de enzimas e toxinas (ex.: cercosporina), que acarretam a morte e a decomposição dos tecidos do hospedeiro (BEDENDO, 2011). Além de ser patogênico, $C$. hibiscina também se desenvolve saprofíticamente em restos culturais e matéria orgânica existente no solo, o que garante a presença de inóculo durante todo o ciclo da cultura. Além disso, o fungo Cercospora possui outros hospedeiros, principalmente plantas do gênero Hibiscus sp., onde pode também se abrigar, consistindo no principal e mais conhecido hospedeiro alternativo do fungo.

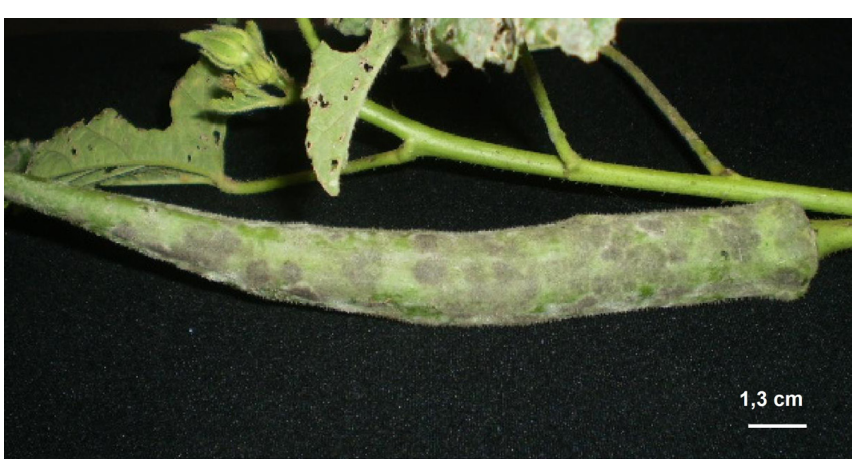

Figura 3. Fruto de Abelmoschus esculentus exibindo sintomas de cercosporiose, causada por C. hibiscina, Universidade Estadual de Goiás, Ipameri, 2013. Manchas grandes (até 1,3 cm de diâmetro), irregulares, de aspecto fuliginoso, com coloração verde-oliva a cinza-escura, espalhadas pelo fruto.

\section{Controle}

Fundamentalmente, o controle da cercosporiose na cultura do quiabeiro é baseado em práticas culturais, controle químico e controle alternativo. Em casos severos, a prática da rotação de culturas com uma espécie não hospedeira, por um período de um a dois anos, pode reduzir o potencial de inóculo na área de cultivo (FARRAG, 2011). Além disso, os restos de cultura devem ser retirados das áreas de plantio após a última colheita e incinerados; somando-se a isso, não se deve iniciar o cultivo próximo a lavouras velhas (HALFELD-VIEIRA et al., 2010). Mesmo que a transmissão pela semente seja pouco provável, é conveniente tratar as sementes com fungicidas protetores para garantir a ausência de Cercospora sp. ou usar sementes livres do patógeno (AGRIOS, 2005).

Segundo Massola Junior e Bedendo (2005), o controle químico curativo é recomendado na ocorrência de surtos epidêmicos, em que este pode ser feito com pulverizações quinzenais com oxicloreto de cobre. No Brasil, boa parte das pesquisas enfocando controle é direcionada ao controle alternativo da cercosporiose, usando produtos como própolis a $1,6 \%$ e leite a $15 \%$, porém sem efeito (SOUZA et al., 2008). Outros produtos alternativos com mais sucesso foram avaliados por Catarino et al. (2007), como extratos aquosos de nim (Azadirachta indica Juss) e de capim citronela (Cymbopogon nardus L.), os quais propiciaram $73 \%$ e $62 \%$ de controle da cercosporiose, respectivamente. Com relação ao controle varietal, não existem relatos de variedades ou cultivares de quiabo com algum tipo de resistência à cercosporiose.

\section{Considerações Finais}

Para a identificação da espécie de Cercospora ocorrente no quiabeiro, é indispensável a obtenção das dimensões do comprimento e da largura do conidióforo e dos conídios do fungo. Resumidamente, P. abelmoschi e Cercospora (C. hibiscina e C. malayensis) podem ser diferenciados, baseando-se nas características dos conidióforos, e C. malayensis e C. hibiscina podem ser diferenciados pelas dimensões dos conidióforos e conídios.

Os sintomas da doença também compreendem caracteres importantes para a correta diagnose. No Brasil, a cercosporiose está frequentemente associada às espécies $C$. malayensis $\mathrm{e}$ C. hibiscina, em que C. malayensis é uma espécie menos agressiva, causando manchas foliares escuras e arredondadas, enquanto $C$. hibiscina é mais agressiva, causando manchas foliares escuras, porém irregulares e maiores que as causadas por C. malayensis

O controle da cercosporiose na cultura do quiabeiro é baseado em práticas culturais (rotação de culturas) e controle químico (oxicloreto de cobre), pois não existem variedades para o controle genético da doença.

\section{Agradecimentos}

Os autores agradecem ao apoio oferecido pelo Programa de Bolsa de Incentivo à Pesquisa e Produção Científica (PROBIP) da Universidade Estadual de Goiás (UEG). 


\section{Referências}

AGRIOS, G. N. Control of plant diseases. In: . (Ed.). Plant pathology. 5th ed. San Diego: Academic Press, 2005. p. 295-357. http://dx.doi.org/10.1016/B978-0-08-047378-9.50015-4.

BAKHSHI, M. et al. Comprehensive check list of Cercosporoid fungi from Iran. Plant Pathology \& Quarantine Chiang Rai, v. 2, n. 1, p. 44-55, 2012. http://dx.doi.org/10.5943/ppq/2/1/7.

BEDENDO, I. P. Manchas foliares. In: BERGAMIN FILHO, A.; AMORIM, L.; REZENDE, J. A. (Ed.). Manual de fitopatologia: princípios e conceitos. Piracicaba: Agronômica Ceres, 2011. p. 459-466. v. 1.

BEGUM, M. M. et al. Taxonomic review of and development of a lucid key for philippine cercosporoids and related fungi. In: CUMAGUN, C. J. (Ed.). Plant pathology. Rijeka: InTech Europe, 2012. p. 1-41.

CATARINO, A. M. et al. Cercosporiose do quiabeiro: métodos alternativos de controle. Porto Seguro: Associação Brasileira Horticultura, 2007. 4 p.

CHUPP, C. A monograph of the fungus genus Cercospora. New York: Ithaca, 1954. $667 \mathrm{p}$.

FARR, D. F.; ROSSMAN, A. Y. Fungal databases. Washington: Systematic Mycology and Microbiology Laboratory, ARS, USDA, 2015. Disponível em: <http://nt.ars-grin.gov/fungaldatabases/ fungushost/fungushost.cfm>. Acesso em: 15 jan. 2015.

FARRAG, E. S. H. First record of Cercospora leaf spot disease on okra plants and its control in Egypt. Plant Pathology Journal, New York, v. 10, n. 4, p. 175-180, 2011. http://dx.doi.org/10.3923/ ppj.2011.175.180.

FREIRE, F. C. O.; BRAUN, U. Hifomicetos cercosporoides associados a plantas do estado do Ceará. Revista Ciência Agronômica, Fortaleza, v. 40, n. 1, p. 150-156, 2009.

GONÇALVES, G. C. et al. Estudo da viabilidade técnica da produção de quiabo (Abelmoschus esculentus L.) e jiló (Solanum gilo) em Planaltina-GO. Brasília: Departamento de Agronomia, Faculdades Integradas, UPIS, 2009. 91 p. (Boletim Técnico).

HALFELD-VIEIRA, B. A. et al. Principais doenças em cultivos de pequenas propriedades do entorno de Boa Vista. Boa Vista: Embrapa Roraima, 2010. 31 p. (Documentos, n. 36).

JAIN, N. et al. A review on: Abelmoschus esculentus. Pharmacia, Gwalior, v. 1, n. 3, p. 84-89, 2012.
LITTLE, S. Cercospora malayensis. CMI Descriptions of Pathogenic Fungi and Bacteria, Wallingford, v. 916, p. 1-2, 1987.

MASSOLA JUNIOR, N. S.; BEDENDO, I. P. Doenças do quiabeiro (Abelmoschus esculentus). In: KIMATI, H. et al. (Ed.). Manual de fitopatologia: doenças das plantas cultivadas. Piracicaba: Agronômica Ceres, 2005. p. 541-543. v. 2.

MEEBOON, J. et al. An annotated list of cercosporoid fungi in Northern Thailand. Journal of Agricultural Technology Bangkok, v. 3, n. 1, p. 51-63, 2007.

MENDES, M. A. S. et al. Fungos em plantas no Brasil. Brasília: Embrapa Recursos Genéticos e Biotecnologia, 1998. 555 p.

MYCOBANK. Cercospora hibiscina. The Netherlands: International Mycological Association, 2015. Disponível em: $<$ http://www.mycobank. org/Biolomics.aspx?Table=Mycobank\&MycoBankNr_=149674>. Acesso em: 15 jan. 2015.

OLIVEIRA, A. P. et al. Rendimento de quiabo em função das doses de nitrogênio. Acta Scientiarum Agronomy Maringá, v. 25, n. 2, p. 265-268, 2003. http://dx.doi.org/10.4025/actasciagron.v25i2.1761.

PANERO, F. S. et al. Aplicação da análise exploratória de dados na discriminação geográfica do quiabo do Rio Grande do Norte e Pernambuco. Eclética Química, São Paulo, v. 34, n. 3, p. 33-40, 2009. http://dx.doi.org/10.1590/S0100-46702009000300004.

PAULA, D. M. G. Cercosporiose (Pseudocercospora abelmoschi Ellis \& Everh.) do quiabo (Abelmoschus esculentus L.). Urutaí: Instituto Federal Goiano, 2011. Disponível em: $<$ http://fitopatologia1. blogspot.com.br/2011/05/cercosporiose-pseudocercospora.html>. Acesso em: 15 jan. 2015.

SOUZA, L. A. et al. Efeito fungicida da própolis e do leite sobre a cercosporiose na cultura do quiabeiro (Abelmoschus esculentus). Revista Brasileira de Agroecologia, Porto Alegre, v. 3, p. 142-145, 2008.

VASCONCElos, C. V.; SILVA, D. C.; CARVAlHO, D. D. C. Ocorrência de Alternaria alternata (Fr.:Fr.) Keissl. em tubérculos de batata, no Brasil. Pesquisa Agropecuária Tropical, Goiânia, v. 44, n. 2, p. 219-222, 2014. http://dx.doi.org/10.1590/S198340632014000200015. 